\title{
Egg and breast milk based nitrogen sources compared
}

\author{
J W L PUNTIS,* P A BALL $†$ M A PREECE, A GREEN, $\ddagger$ G A BROWN,* AND I W BOOTH* \\ ${ }^{*}$ Institute of Child Health, University of Birmingham, and $¥$ Departments of Clinical Chemistry and \\ tPharmacy, The Children's Hospital, Birmingham
}

SUMMARY A nitrogen source based on egg protein (Vamin 9 glucose) and an alternative with an amino acid profile more similar to breast milk (Vaminolact), were compared in 14 parenterally fed infants. Subjects were randomly allocated to receive one or other amino acid solution, but were otherwise given identical diets. At the start of the study the two groups did not differ significantly in postconceptual age, postnatal age, or weight. Over a six day study period on a stable intake of intravenous nutrients there was no significant difference in growth or nitrogen retention between the two groups. Plasma amino acid profiles in those receiving Vamin 9 glucose, however, were frequently abnormal. Notably, mean concentrations of potentially neurotoxic phenylalanine and tyrosine were significantly higher (140\% and $420 \%$, respectively) in patients fed Vamin 9 compared with those given Vaminolact. An amino acid solution based on the composition of breast milk protein therefore brings plasma amino acid profiles during parenteral nutrition closer to those found in breast fed infants, and reduces in particular, the risks of hyperphenylalaninaemia and hypertyrosinaemia.

Over the past 20 years intravenous feeding has become a standard form of nutritional support for sick infants. Although the indications for its use in preterm neonates may be poorly defined, there is no doubt that parenteral nutrition has transformed the prognosis for newborns when severe congenital or acquired bowel disease precludes enteral feeding. ${ }^{1}$ Synthetic crystalline L-amino acid solutions such as Vamin (KabiVitrum), which is based on the amino acid profile of egg protein, have commonly been used as the nitrogen source for parenterally fed children, although they were originally designed for adults. Compared with breast milk (table 1), this results in overprovision of some amino acids (such as phenylalanine) but underprovision of others (such as taurine) that are now considered essential for patients on long term parenteral nutrition. ${ }^{2}$

An additional consideration is that, in contrast to older patients, the most appropriate profile of amino acids administered to newborn infants may not only be different but much less flexible. The need for growth means that the young infant
Table 1 Daily intake of individual amino acids/kg body weight for infant receiving $2.5 \mathrm{~g} / \mathrm{kg} /$ day intravenous amino acids or $150 \mathrm{ml} / \mathrm{kg} /$ day breast milk

\begin{tabular}{lrrr}
\hline & $\begin{array}{l}\text { Vamin } \\
\text { glucose }\end{array}$ & Breast milk & Vaminolact \\
\hline Alanine & 107 & 78 & \\
Glycine & 75 & 48 & 250 \\
Proline & 288 & 180 & 83 \\
Valine & 153 & 130 & 222 \\
Threonine & 107 & 87 & 143 \\
Lysine & 139 & 135 & 143 \\
Serine & 267 & 81 & 222 \\
Glutamic acid & 320 & 337 & 151 \\
Leucine & 189 & 180 & 282 \\
Taurine & 0 & 9 & 278 \\
Histidine & 85 & 46 & 13 \\
Arginine & 117 & 73 & 83 \\
Tyrosine & 18 & 57 & 163 \\
Phenylalanine & 196 & 72 & 20 \\
Isoleucine & 139 & 100 & 108 \\
Cystine & 50 & 37 & 123 \\
Tryptophan & 36 & 45 & 40 \\
Methionine & 68 & 28 & 56 \\
Aspartic acid & 146 & 165 & 52 \\
\hline
\end{tabular}


requires relatively larger quantities of essential amino acids than an older child or adult. Furthermore, immaturity of enzyme systems in the neonatal liver may reduce the capability for synthesis and catabolism of certain amino acids. For example, liver cystathionase activity is low at full term, and endogenous synthesis of cystine from methionine is limited, making cystine an essential amino acid in the neonate. In addition, although histidine is not considered essential for adults, it seems to be required for normal growth in newborn infants. ${ }^{3}$

We recently showed that plasma amino acid profiles in babies fed with a conventional amino acid source often show increased concentrations of potentially neurotoxic phenylalanine. ${ }^{4}$ Others have shared our concern, ${ }^{56}$ and debate continues over the optimum composition of parenteral feeding solutions. ${ }^{7}$ Attempts have been made to design amino acid preparations suited to the particular requirements of newborn infants, in some instances with the aim of producing a plasma amino acid profile during parenteral feeding that is similar to that found in breast fed babies. ${ }^{8}$ We have therefore compared amino acid profiles, growth, and nitrogen balance during the use of our usual amino acid solution (Vamin 9 glucose), with a modified formulation containing an amino acid profile more similar to breast milk (Vaminolact, KabiVitrum), in a group of babies admitted to a regional neonatal surgical unit.

\section{Patients and methods}

The study was an open, prospective trial, with random allocation of patients to receive either Vamin 9 glucose or Vaminolact. Only patients less than 3 months of age were included. Infants below the 10th weight centile for age, those with heart failure, liver or renal impairment, or known metabolic defects, uncontrolled sepsis or receiving partial enteral feeding were excluded.

\section{GROUP RECEIVING VAMIN 9 GLUCOSE}

A group of seven patients received Vamin 9 glucose after operations for the following: small bowel volvulus $(n=1)$, gastroschisis $(n=2)$, small bowel atresia $(n=2)$, and necrotising enterocolitis $(n=2)$. At the start of total parenteral nutrition the median postconceptual age was 38 weeks (range 31-42), median weight $2470 \mathrm{~g}$ (range 1470-2910), and median age 16 days (range 11-29).

\section{GROUP RECEIVING VAMINOLACT}

A group of seven patients received Vaminolact after operations for gastroschisis $(n=3)$ and necrotising enterocolitis $(n=4)$. At the start of total parenteral nutrition, the median postconceptual age was 39.5 weeks (range 31-43), median weight $2320 \mathrm{~g}$ (range 1070-3200) and median age 36 days (range 11-84).

\section{NUTRITIONAL INTAKE}

Total parenteral nutrition was prescribed for all patients in accordance with a standard protocol and administered by central venous catheter. ${ }^{9}$ Intakes/ $\mathrm{kg}$ body weight were progressively increased over the first six days of feeding and then maintained at constant amounts as follows: carbohydrate, $8 \mathrm{~g}$, $10 \mathrm{~g}, 10 \mathrm{~g}, 12 \mathrm{~g}, 12 \mathrm{~g}, 14 \mathrm{~g}$; amino acids, $0.5 \mathrm{~g}, 1.0 \mathrm{~g}$, $1.5 \mathrm{~g}, 2.0 \mathrm{~g}, 2.5 \mathrm{~g}$; fat, $1 \mathrm{~g}, 2 \mathrm{~g}, 2 \mathrm{~g}, 3 \mathrm{~g}, 3 \mathrm{~g}, 3.5 \mathrm{~g}$. The maximum daily energy intake was therefore 0.41 $\mathrm{MJ} / \mathrm{kg}$. Detailed records of intravenous infusions including additional peripheral infusions were kept so that precise calculation of intakes of fluid, electrolytes, and nutritional components could be made.

\section{ANTHROPOMETRY}

Patients were weighed daily to the nearest $10 \mathrm{~g}$ using electronic scales (Seca). Additional anthropometric measurements were made on day 0 and day 6 by a single experienced observer; head circumference was measured to the nearest $0 \cdot 1 \mathrm{~cm}$ using a paper tape measure, and triceps and subscapular skinfold thickness to the nearest $0.2 \mathrm{~mm}$ with skin calipers (Holtain Ltd).

HAEMATOLOGICAL AND BIOCHEMICAL MONITORING Infusion of Intralipid was suspended at 5 am each morning until venous blood from a peripheral vein was sampled, between 9 and $10 \mathrm{am}$. Vamin was constantly infused through the central venous feeding catheter and was not interrupted before the peripheral blood was sampled. Blood was taken on the day after the maximum intake of nutrients was reached (day 0 ) and then 72 and 144 hours later. In addition to plasma amino acid profile, estimation of sodium, potassium, creatinine, albumin, total bilirubin, calcium, phosphate, magnesium, glucose, and haemoglobin concentrations, full blood count, and alanine aminotransferase and $\gamma$ glutamyltranspeptidase activities were also carried out. Plasma for amino acid analysis was deproteinised by addition of an equal volume of $3 \%$ sulphosalicylic acid immediately after collection. The supernatant was then stored at $-20^{\circ} \mathrm{C}$ until analysis. Plasma concentrations were measured with a Kontron Chromakon 500 amino acid analyser using a lithium buffer system and ninhydrin detection.

NITROGEN BALANCE

All urine, ileostomy, and nasogastric losses were 
collected during the final 72 hours of the study for subsequent analysis of nitrogen content. During this period patients were nursed on a metabolic bed placed inside an incubator. ${ }^{10}$ Urine, nasogastric aspirate, and ileostomy specimens were stored at $4^{\circ} \mathrm{C}$ until the 72 hour collection was completed. As subjects received no enteral feed during the study, stool losses from the rectum were minimal and were ignored. Specimens were homogenised, total volume measured, and then $20 \mathrm{ml}$ aliquots stored at $-20^{\circ} \mathrm{C}$ until analysis. Nitrogen content was determined using the micro Kjeldahl method ${ }^{11}$ and phenol-hypochlorite (Bertholet) reaction.

\section{STATISTICAL ANALYSIS}

Comparisons between groups of clinical characteristics, plasma amino acid concentrations, and nitrogen retention were made by the Mann-Whitney $U$ test. Other biochemical observations were compared by Student's $t$ test. The mean concentration of each

Table 2 Growth during study period

\begin{tabular}{lll}
\hline & Vamin 9 glucose & Vaminolact \\
\hline $\begin{array}{l}\text { Median daily increase in } \\
\text { weight (range) }\end{array}$ & $\begin{array}{l}37 \mathrm{~g} \\
(23-60)\end{array}$ & $\begin{array}{l}32 \mathrm{~g} \\
(10-38)\end{array}$ \\
$\begin{array}{c}\text { Median increase in triceps } \\
\text { skinfold thickness during } \\
\text { six day study (range) }\end{array}$ & $\begin{array}{c}0.6 \mathrm{~mm} \\
(0-1.6)\end{array}$ & $\begin{array}{c}0.4 \mathrm{~mm} \\
(0-0.6)\end{array}$ \\
$\begin{array}{l}\text { Median increase in subscapular } \\
\text { skinfold thickness during } \\
\text { six day study (range) }\end{array}$ & $\begin{array}{c}0.4 \mathrm{~mm} \\
(0.2-3.0)\end{array}$ & $\begin{array}{c}0.4 \mathrm{~mm} \\
(0-0.4)\end{array}$ \\
$\begin{array}{l}\text { Median increase in head } \\
\text { circumference during six } \\
\text { day study (range) }\end{array}$ & $\begin{array}{c}0.6 \mathrm{~cm} \\
(0-1.2)\end{array}$ & $\begin{array}{c}0.4 \mathrm{~cm} \\
(0-0.9)\end{array}$ \\
\hline
\end{tabular}

amino acid was calculated after $\log _{10}$ transformation of all the measurements made in one group throughout the study period. Within group changes in variables from day 0 to day 6 were compared using a paired $t$ test. A probability of $<0.05$ was accepted as significant.

Approval for the study was obtained from the research ethical committee of the Central Birmingham Health Authority. Informed parental consent was obtained before starting total parenteral nutrition.

\section{Results}

There were no significant differences between patients given Vamin 9 glucose and those given Vaminolact in age in days, postconceptual age, weight at the start of total parenteral nutrition, or intakes of fluid, nitrogen, carbohydrate, or energy. No adverse reactions to feeding solutions were seen in either group and no patients were septic during the period of study.

\section{ANTHROPOMETRY}

Each group showed a significant increase in weight, head circumference, and triceps skinfold thickness over the six day study period $(\mathrm{p}<0.05)$ (table 2$)$. Increases in subscapular skinfold thickness were not significant. Median weight gain was $37 \mathrm{~g} /$ day (range 23-60 g) in the Vamin 9 glucose group, and $32 \mathrm{~g}$ $(10-38 \mathrm{~g})$ in the Vaminolact patients $(\mathrm{p}=0 \cdot 26)$. No significant differences were found in changes in other anthropometric variables between groups.

NITROGEN BALANCE

The median nitrogen intake for Vamin 9 glucose

Table 372 Hour nitrogen balance

\begin{tabular}{|c|c|c|c|c|c|}
\hline Weight $(g)$ & Nitrogen intake (mg) & $\begin{array}{l}\text { Urinary nitrogen } \\
\text { loss }(\dot{m g})\end{array}$ & $\begin{array}{l}\text { Nasogastric nitrogen } \\
\text { loss (mg) }\end{array}$ & $\begin{array}{l}\text { lleostomy nitrogen } \\
\text { loss (mg) }\end{array}$ & $\begin{array}{l}\text { Nitrogen } \\
\text { retention (\%) }\end{array}$ \\
\hline \multicolumn{6}{|c|}{ Group receiving Vamin 9 glucose } \\
\hline 2550 & 2340 & 228 & 118 & 0 & 85 \\
\hline 1470 & 1215 & 225 & 7 & 17 & 80 \\
\hline 2470 & 2175 & 330 & 128 & 0 & 79 \\
\hline 2910 & 2262 & 490 & 66 & 0 & 75 \\
\hline 2000 & 1800 & 525 & 23 & 0 & 70 \\
\hline 1930 & 1653 & 460 & 0 & 0 & 72 \\
\hline 2630 & 1872 & 904 & 0 & 0 & 52 \\
\hline \multicolumn{6}{|c|}{ Group receiving Vaminolact } \\
\hline 2550 & 2340 & 343 & 0 & 0 & 85 \\
\hline 3200 & 2304 & 453 & 0 & 0 & 80 \\
\hline 2740 & 2187 & +40 & 14 & 0 & 79 \\
\hline 2320 & 1863 & 347 & 0 & 139 & 74 \\
\hline 1070 & 957 & 278 & 4 & 0 & 70 \\
\hline 1440 & 1210 & 404 & 0 & 171 & 52 \\
\hline 2180 & 1584 & 875 & 17 & 0 & 44 \\
\hline
\end{tabular}


Table 4 Mean (range) plasma amino acid concentrations (umolll) in patients receiving Vamin 9 glucose and Vaminolact

\begin{tabular}{|c|c|c|c|c|}
\hline Amino acid & Target range ${ }^{12}$ & Vamin 9 glucose & Vaminolact & p Value \\
\hline Alanine & $125-647$ & $251(87-872)$ & $305(125-509)$ & $0 \cdot 66$ \\
\hline Glycine & $77-376$ & $460(232-937)$ & $448(220-701)$ & $0 \cdot 68$ \\
\hline Proline & $83-319$ & $312(85-458)$ & $153(171-356)$ & 0.03 \\
\hline Valine & $88-222$ & $222(69-331)$ & $152(106-237)$ & 0.0002 \\
\hline Threonine & $70-197$ & $248(70-440)$ & $367(145-699)$ & 0.003 \\
\hline Lysine & $80-232$ & $82(43-195)$ & $206(71-388)$ & 0.0001 \\
\hline Serine & $0-326$ & $268(86-689)$ & $218(110-579)$ & $0 \cdot 15$ \\
\hline Glutamic acid & $24-243$ & $78(20-764)$ & $98(40-550)$ & 0.8 \\
\hline Leucine & $53-169$ & $94(49-144)$ & $108(47-226)$ & 0.03 \\
\hline Taurine & $1-167$ & $48(24-186)$ & $88(52-245)$ & 0.01 \\
\hline Histidine & $34-119$ & $92(50-153)$ & $99(60-145)$ & $0 \cdot 5$ \\
\hline Arginine & $42-148$ & $32(16-78)$ & $51(21-148)$ & 0.0005 \\
\hline Tyrosine & $38-119$ & $146(43-572)$ & $28(5-69)$ & 0.0004 \\
\hline Phenylalanine & $22-70$ & $192(55-800)$ & $80(47-167)$ & 0.0028 \\
\hline Isoleucine & $27-90$ & $55(11-124)$ & $50(22-100)$ & 0.029 \\
\hline Cystine/cysteine & 99-208 & $52(25-108)$ & $38(10-70)$ & 0.047 \\
\hline Tryptophan & $19-100$ & $30(20-42)$ & $49(26-69)$ & 0.0001 \\
\hline Methionine & $22-50$ & $39(12-69)$ & $25(13-40)$ & 0.0001 \\
\hline Aspartic acid & $5-51$ & $19(7-73)$ & $23(12-72)$ & $0 \cdot 6$ \\
\hline
\end{tabular}

patients was $857 \mathrm{mg} / \mathrm{kg} / 72$ hours (range 712-918) and for Vaminolact patients $803 \mathrm{mg} / \mathrm{kg} / 72$ hours (range 720-916). The median nitrogen retention calculated from the three day balance study was $75 \%$ (range $52-85$ ) for Vamin 9 glucose and $74 \%$ (range 44-85) for Vaminolact (table 3). The nitrogen intakes and retentions were not significantly different between the groups.

\section{HAEMATOLOGICAL AND BIOCHEMICAL MEASUREMENTS}

No haematological or biochemical measurements changed significantly in either group over the six day study period. In particular, no patients showed biochemical evidence of liver dysfunction. Other than plasma amino acid concentrations, no haematological or biochemical measurements in the two groups were significantly different.

\section{PLASMA AMINO ACID PROFILES}

For each group, the mean and range of plasma concentrations for individual amino acids are shown in table 4 ; the quoted target ranges represent the $95 \%$ confidence interval derived from amino acid profiles in breast fed infants. ${ }^{12}$ Few amino acids were consistently found at concentrations within the target range. Phenylalanine concentrations in subjects fed Vaminolact were significantly lower than in the Vamin 9 group $(p=0.0028)$ as were concentrations of tyrosine $(p=0 \cdot 0004)$. In the group given Vaminolact, $80 \%$ of the tyrosine values fell below, and $20 \%$ within, the target range, while in the Vamin 9 group $58 \%$ were above the upper target range and none below. Total cystine/cysteine concentrations always fell below the lower target range in the Vaminolact group, and only one value in the Vamin 9 group was above this. In the subjects fed Vaminolact, the mean concentrations of all amino acids except threonine, lysine, histidine, and cystine were closer to the reference means than in Vamin 9 glucose fed infants. ${ }^{12}$

\section{Discussion}

The results of this study indicate that the use of a neonatally adapted amino acid source leads to a reduction in the derangement of plasma amino acid profiles, while growth and nitrogen retention are unchanged. Previous studies have shown that plasma phenylalanine is higher in parenterally fed babies than in those receiving enteral feeds, ${ }^{13}{ }^{14}$ and particular attention has been drawn to the observation that high phenylalanine intakes in neonates receiving Vamin 9 glucose may be associated with potentially neurotoxic plasma phenylalanine concentrations. ${ }^{4-6}$ Two of the seven babies given Vamin 9 glucose during this study had plasma phenylalanine concentrations above $600 \mu \mathrm{mol} / \mathrm{l}$, which would be considered unacceptably high in a child with treated phenylketonuria. ${ }^{15}$ Phenylalanine concentrations in children receiving Vaminolact were much lower $(p=0.0028)$, although a high proportion $(68 \%)$ were still above the upper limit of the target range.

There are several reasons why plasma amino acid profiles in patients given Vaminolact still differ from 
those in breast fed infants. An intravenous amino acid intake of $2.5 \mathrm{~g} / \mathrm{kg} /$ day is $25 \%$ higher than with breast milk of average composition. Furthermore, plasma amino acid profiles in breast fed infants reflect modification of relative amino acid concentrations during small intestinal absorption and subsequent passage of portal blood through the liver. That such modification occurs is one reason why attempts to reproduce those plasma amino acid profiles found in breast fed infants exactly in parenterally fed infants are probably misguided.

The mean tyrosine concentration in infants fed Vamin 9 glucose was also high compared with that reported in breast fed infants, ${ }^{12}$ and tyrosine concentrations were significantly higher than those found in the Vaninolact group ( $p=0 \cdot 0004)$. This too is a cause for concern, as it has been suggested that raised tyrosine concentrations may be related to long term developmental impairment. ${ }^{16}$ The raised tyrosine concentrations probably reflect phenylalanine catabolism, as the intake of tyrosine with both Vamin 9 glucose and Vaminolact is similar. The low mean concentration of tyrosine found in the Vaminolact group suggests possible underprovision of this amino acid, which is said to be 'semiessential' in the very low birthweight infant. This might pose problems in long term parenteral nutrition, although the consequences of a low tyrosine intake are unknown.

The increased threonine concentrations with Vaminolact reflect the fact that intake of threonine is about $50 \%$ higher than in the Vamin 9 glucose or breast fed infants, but does not exceed the recommended maximum for preterm infants. ${ }^{17}$ Although concentrations of cystine/cysteine were low, clinical studies have shown that cystine deficient diets have no apparent adverse effects on growth or nitrogen balance in preterm infants and the precise requirements for cystine remain unknown. ${ }^{18} 19$

The implications of the hyperphenylalaninaemia observed in the Vamin 9 glucose group are difficult to assess. Recent evidence suggests that appreciable intellectual impairment may occur in patients with phenylketonuria even when plasma phenylalanine concentrations have been kept as low as 600 $\mu \mathrm{mol} / \mathrm{l} .^{20}$ Although courses of parenteral nutrition will in most cases be measured in weeks rather than months, the neonatal brain is undergoing a period of rapid growth and development and might therefore be particularly sensitive to injury. Studies in animals have shown that even transient rises of plasma phenylalanine may be associated with enduring behavioural changes ${ }^{21}$ and poor brain growth. ${ }^{22}$ High concentrations of phenylalanine during parenteral nutrition must therefore be regarded as potentially harmful. The widespread experience with Vamin 9 glucose suggests, however, that the risk of clinically apparent neurological injury in the short term is extremely small.

Amino acid solutions such as Vaminolact that are specifically designed to meet the needs of infants are likely to lessen the risk of neurotoxicity resulting from amino acid imbalance, and we now use a neonatally adapted formula (Vamin Infant ${ }^{*}$ ) in patients less than 6 months of age. We reject the view that measurement of plasma amino acid concentrations during parenteral nutrition is unnecessary, ${ }^{23}$ and recommend weekly monitoring - at least of phenylalanine-in patients up to 6 months of age who are receiving an unmodified, high phenylalanine, amino acid solution.

*Vamin Infant is available in the United Kingdom and is identical to Vaminolact except that it does not contain taurine. Vaminolact does not yet have a product licence in the United Kingdom.

We thank the nursing staff of Ward PB2 whose skills, help, and enthusiasm made this study possible, and Dr R Wild of KabiVitrum for supplying the Vaminolact. We also thank the department of medical physics, Birmingham Maternity Hospital, and the Central Birmingham Health Authority workshops for constructing the metabolic bed, the plans for which were kindly provided by Dr MG Coulthard.

Dr JWL Puntis performed this study while holding a Sheldon Clinical Research Fellowship from the West Midlands Regional Health Autority.

\section{References}

1 Dorney SFA, Ament ME, Berquist WE, Vorgas JH, Hassall E Improved survival in very short small bowel of infancy with use of long-term parenteral nutrition. J Pediatr 1985;107:521-5.

2 Geggel HS, Ament ME, Heckenlively JR, Martin DA, Kopple JD. Nutritional requirement for taurine in patients receiving long-term parenteral nutrition. $N$ Engl $J$ Med 1985;312:142-6.

3 Snyderman SE, Boyer A, Roitman E, Holt LE, Prose PH. The histidine requirements of infants. Pediatrics 1963;31:786-801.

${ }^{4}$ Puntis JWL, Edwards MA, Green A, Morgan I, Booth IW, Ball PA. Hyperphenylalanaemia in parenterally fed newborn babies. Lancet 1986;ii:1105-6.

5 Walker V, Hall MA, Bulusu S, Allan A. Hyperphenylalanaemia in parenterally fed newborn babies. Lancet 1986;ii: 1284

6 Evans SJ, Wynne-Williams TCJE, Russell CA, Fairbrothe: A. Hyperphenylalaninaemia in parenterally fed newborn babies. Lancet 1986;ii:1404-5.

7 Lemons JA, Neal P, Ernst J. Nitrogen sources for parenteral nutrition in the newborn infant. Clin Perinatol 1986;13:91-109.

${ }^{8}$ Heird WC, Dell RB, Helms RA, et al. Amino acid mixture designed to maintain normal plasma amino acid patterns in infants and children requiring parenteral nutrition. Pediatrics 1987;79:401-8.

${ }^{9}$ Hughes CA. Parenteral nutrition. In: Insley J, Wood B, eds. A paediatric vade mecum. London: Lloyd-Luke, 1984:60-7.

10 Coulthard MG. Device for continuous urine collection in the newborn. Arch Dis Child 1982;57:322.

11 Fleck A, Munro HN. The determination of organic nitrogen in biological materials. Clin Chim Acta 1965;11:2-12.

12 Wu PYK, Edwards N, Storm MC. Plasma amino acid pattern in normal breast fed infants. J Pediatr 1986;109:347-9.

13 Hume R, Giles MM, Cockburn F. Amino acid analysis in parenteral nutrition of the newborn. In: Rattenbury JM, ed. Amino acid analysis. Chichester: Horwood, 1981:131-8. 
14 Rigo J, Senterre J. Parenteral nutrition in the very low birth weight infant. In: Krechmer N, Minkowski A, eds. Nutritional adaptation of the gastrointestinal tract of the newborn. New York: Nestle, Vevey/Raven Press, 1983:191-207.

is Tourian A, Sidbury JB. Phenylketonuria. In: Stanbury JB, Wyngaarden JB, Fredrickson DS, eds. The metabolic basis of inherited disease. New York: McGraw Hill, 1982:270-86.

${ }^{16}$ Mamunes P, Prince PE, Thornton NH, Hunt PA, Hitchcock ES. Intellectual deficits after transient tyrosinaemia in the term neonate. Pediatrics 1976;57:675-80.

17 Rigo J, Senterre J. Optimal threonine intake for preterm infants fed on oral or parenteral nutrition. JPEN 1979;4:15-7.

18 Malloy MH, Rassin DK, Richardson CJ. Total parenteral nutrition in sick pre-term infants: Effects of cysteine supplementation with nitrogen intakes of 240 and $400 \mathrm{mg} / \mathrm{kg} /$ day. $J$ Pediatr Gastroenterol Nutr 1984;3:239-44.

19 Zlotkin SH, Bryan MH, Anderson GH. Cysteine supplementation to cysteine free intravenous feeding regimens in newborn infants. Am J Clin Nutr 1981;34:914-23.
${ }^{20}$ Wolff $\mathrm{O}$, Smith I, Beasley M. Quelques limites de la classification et de la nomenclature des hyperphenylalaninemies. Arch Fr Pediatr 1987;44:635-8.

21 Andersen AE, Guroff G. Enduring behavioural changes in rats with experimental phenylketonuria. Proc Natl Acad Sci USA 1972;69:863-8.

22 Prensky AL, Fishman MA, Daftari B. Recovery of rat brain from a brief hyperphenylalaninaemic insult early in development. Brain Res 1974;73:51-6.

${ }^{23}$ Kerner JA. Monitoring of pediatric parenteral nutrition in the hospital and at home. In: Lebenthal E, ed. Total parenteral nutrition. New York, Raven Press 1986:231-44.

Correspondence and requests for reprints to Dr JWL Puntis, Institute of Child Health, Francis Road, Edgbaston, Birmingham B16 8ET.

Accepted 2 June 1989 